\title{
Training of health personnel to improve knowledge and skills in taking Pap: Effect of an educational intervention to prevent cervical cancer $^{*}$
}

\author{
Gutiérrez-Enríquez Sandra Olimpia ${ }^{1 \#}$, Frías-Navarro Víctor Omar², Oros-Ovalle Cuauhtémoc ${ }^{3}$, \\ Ortiz-Valdez Julio Alejandro ${ }^{4}$, Gaytán-Hernández Darío ${ }^{1}$, Terán-Figueroa Yolanda ${ }^{1}$ \\ ${ }^{1}$ Nursing Faculty, San Luis Potosí University, San Luis Potosí, México; ${ }^{\#}$ Corresponding Author: sgutierr@uaslp.mx \\ ${ }^{2}$ Guanajuato University, Guanajuato, México \\ ${ }^{3}$ Patology Deparment, Dr. Ignacio Morones Prieto Central Hospital, San Luís Potosí, México \\ ${ }^{4}$ Colposcopy Department from Child and Women's Hospital, Health Services from San Luis Potosí, San Luis Potosí, México
}

Received 24 April 2013; revised 26 May 2013; accepted 1 July 2013

Copyright (C) 2013 Gutiérrez-Enríquez Sandra Olimpia et al. This is an open access article distributed under the Creative Commons Attribution License, which permits unrestricted use, distribution, and reproduction in any medium, provided the original work is properly cited.

\section{ABSTRACT}

Objective: To evaluate the effectiveness of an educational intervention to improve knowledge and skills in taking Pap smear conducted by health staff implementing the program on Early Detection of Cervical Cancer. Methods: A quasiexperimental, longitudinal and prospective study, held from October 252010 to April 11, 2011 at a hospital in San Luis Potosi, Mexico. To select groups applied a non-probabilistic convenience sampling that was composed of 28 people, 15 for the study group and $\mathbf{1 3}$ to the control group. The study group received training that was divided into three phases in which assessed the knowledge and skills taking the smear, the control group received conventional training offered by your workplace. Papanicolaou quality was measured before and after the intervention. The reference used international classification system Bethesda 2001. For data analysis we used the Student $t$ test. Results: The study group increased knowledge $(t=8.768, p=0.000)$ in the management of official standards, in the anatomy of the lower female genital tract and in the form of testing. Technical skills $(t=8.639, p=$ 0.000 ) also increased in the study group after the intervention. The control group showed no significant changes. The quality report of the samples in the study group increased from $60 \%$ to

\footnotetext{
${ }^{*}$ This project was supported by the Found for the Promotion of Scientific and Technological Research CONACYT-State Government of San Luis Potosi, México (FMSLP-2008-C01-85575).
}

$86.7 \%$ and in the control group decreased from $92.3 \%$ to $84.6 \%$. Conclusions: The training is effective in improving the knowledge and skills in taking Pap. Health staff who received the training improved their performance and showed more interest in providing high quality service to women.

Keywords: Cervical Cancer; Educational Intervention Pap; Knowledge and Skills in Taking Pap

\section{INTRODUCTION}

Cervical cancer (CC) is a public health problem worldwide and the second most common cancer among women worldwide with estimated 493,000 new cases and 274,000 deaths in 2002 . About $83 \%$ of cases occur in developing countries, with a cumulative risk before 65 years of age of $1.5 \%$. In developed countries, cervical cancer represents $3.6 \%$ of new cancer cases, with a cumulative risk of $0.8 \%$ [1]. In Latin America it is one of the leading causes of death in women and 33,000 die each year because of this problem and it is estimated that this trend continues, the number could double by the year 2030 [2], the high incidence of this condition is a reflection of the lack of efficiency of preventive programs for management [3].

In Mexico it was reported in 2005 national mortality rate of 15.46 per 100,000 women, while in San Luis Potosi was 19.30, higher than the national average [4]. For the same year, the country reported 495,240 deaths, and of these malignant tumors are the third and $13.3 \%$ 
corresponds to $\mathrm{CC}$ directly impacting the female population. It is increasingly common to see young women between 20 and 30 years with this disease [5]. In the state of San Luis Potosi for 2005 recorded adjusted mortality rate of 19.3 , with 116 deaths [6] one woman dies from cervical cancer every other day.

Results published by the Central American Health Institute (ICAS), revealed that a number of factors ranging from poor quality with running early detection programs at all levels and sectors, are public, private or social security, to insufficient and inadequate staff training, coupled with the lack of human resources, clinical information, poor supervision and monitoring of cases in screening centers. The problem is common: the poor quality in the process of making cytology and analysis as the heart of the problem [7]. In Mexico there is great variability in heterogeneous technical effectiveness and quality levels by region and public and private institutions, indicating the need to develop indicators and standards to improve the performance of service providers [8].

While today there are other methods of detection and prevention methods like the vaccine and the human papillomavirus test, today in undeveloped countries Pap smear is most affordable and accessible to all people, especially the low resources, on the other hand, decreasing the incidence takes years to arrive, once we see any effects of protection in vaccinated cohorts. The purpose of this study is to evaluate the effect of an educational intervention targeted health personnel to improve knowledge and skills in taking the Papanicolaou.

\section{MATERIAL AND METHODS}

\subsection{Study Design}

The design is quasi-experimental, longitudinal and prospective, performed in a public hospital in the city of San Luis Potosi, México, from October 25, 2010 to April 11, 2011. 28 Doctors and Nurses participated whose function is to take the Pap. To select the groups applied a no probabilistic convenience sampling (15 for the study group and 13 to the control group) selected according to the needs of the institution and the availability of the staff to attend training.

\subsection{Educational Intervention}

The educational intervention was implemented as training for the study group. Was integrated by 3 phases with a total duration of 50 hours: Phase I: Systematization of the experience, obtained through a meeting. Each person explained the main constraints and facilitators in taking the smear. Phase II: Measuring baseline. We applied a test of knowledge and the skills, which were observed in both groups. The study group performed
4 practices on patients and 2 practices sessions with support materials through modeling of the cervix with soap and other practice with anatomical specimen (beef uterus). The pathologist read the samples in the presence of the participants and pointed out the errors. Knowledge was reinforced through audio and video material. The quality of Pap was obtained through the lab report. Phase III: Final Evaluation. We applied the same test of knowledge and skills, to the both groups. The control group had conventional training provided to them in their workplaces.

\subsection{Source of Data}

The knowledge test consisted of three sections: the Official Mexican Standards, the anatomy of the female lower genital tract and the procedure for the Pap. In this section we considered the knowledge of records, material used, gynecologic evaluation, counseling before, during and after the procedure, types of tools for the take Pap, end the technique Papanicolaou (obtaining, spread and fixation) and processing of the slide after the test. To measure the knowledge, we designed a quantitative scale $(0-57)$ to obtain the average score for each person. To measure the general level of knowledge in a structured qualitative ordinal scale based on the number of hits: High (45 - 57 points), Medium (32 - 44 points) and Low (0 - 31 points).

To qualify as technical skills in taking Pap designed a checklist that was rated as inadequate ( 0 - 77 points $)$ and adequate (78 - 98 points) Total 98 points. We evaluated five basic points: receiving user, material preparation, data recording in the application form and on the slide, preparation of the user and the technical of taking the smear, which was evaluated according to manual current procedures in the official rules. All samples were taken with cytobrush and Ayre spatula and fixed with spray. The reliability of the instrument was measured using Cronbach's alpha 0.74 for the survey and 0.80 for the checklists, the validity was conducted by experts in the field. Pap quality was obtained through the pathology report, previously designed a checklist based on the 2001 Bethesda System.

\subsection{Statistical Analysis}

To verify the difference between study and control groups with respect to knowledge and skills applied the Student $\mathrm{t}$ test for independent samples.

\subsection{Ethical Criteria}

To implement this study took into consideration the ethical principles contained in the Declaration of Helsinki. All participants gave informed consent in writing. The project was approved by the $\mathrm{H}$. Bioethics and 
Research Committee of the Health Services of San Luis Potosi and the School of Nursing from San Luis Potosí University from México.

\section{RESULTS}

Before the educational intervention study group had a mean of 25.93 and 27.54 in control group of the knowledge for taking Pap (total score 0 - 57), it was found that no significant difference $(\mathrm{t}=0.735, \mathrm{p}=0.469)$ between the means of knowledge of each group. After the educational intervention was performed again the comparison of means (study group 49.40 and control group 30.69) finding a significant difference for the study group $(\mathrm{t}=8.768, \mathrm{p}=0.000)$ (Table 1$)$.

The average score in the technical skills for taking the Papanicolaou (score 0 - 98) in the study group was 20.27 and 22.23 for the control group. No significant difference between the groups before the intervention $(\mathrm{t}=1.158, \mathrm{p}=$ 0.258 ). After the intervention the study group had a mean of 39.33 and 24.69 for the control group, comparing final averages of the groups was a significant difference for the study group $(\mathrm{t}=8.639, \mathrm{p}=0.000)$ (Table 2$)$.

There were four practices with patients in the educational intervention. The first and last were taken as input and output practices, also were two other intermediate practices in order to examine the variability in the average rating of all. Skills were increased from the first practice (Figure 1).

Table 1. Knowledge in taking the Pap test before and after an educational intervention.

\begin{tabular}{ccccc}
\hline $\begin{array}{c}\text { Overall Knowledge Score } \\
(0-57)\end{array}$ & $\begin{array}{c}\text { Pre-Intervention } \\
\text { Groups }\end{array}$ & $\begin{array}{c}\text { Post-Intervention } \\
\text { Groups }\end{array}$ \\
\hline & $\begin{array}{c}\text { Study } \\
\mathrm{n}=15\end{array}$ & $\begin{array}{c}\text { Control } \\
\mathrm{n}=13\end{array}$ & $\begin{array}{c}\text { Study } \\
\mathrm{n}=15\end{array}$ & $\begin{array}{c}\text { Control } \\
\mathrm{n}=13\end{array}$ \\
Average & 25.93 & 27.54 & 49.40 & 30.69 \\
Standard Desviation & 5.29 & 6.26 & 3.08 & 7.58 \\
& $\mathrm{t}=0.735$ & $\mathrm{t}=8.768$ \\
$\mathrm{p}=0.469$ & $\mathrm{p}=0.000$ \\
\hline
\end{tabular}

Table 2. Skills in taking Pap before and after an educational intervention.

\begin{tabular}{ccccc}
\hline $\begin{array}{c}\text { Skills in Taking Pap } \\
(0-98)\end{array}$ & \multicolumn{2}{c}{$\begin{array}{c}\text { Pre-Intervention } \\
\text { Groups }\end{array}$} & $\begin{array}{c}\text { Post-Intervention } \\
\text { Groups }\end{array}$ \\
& $\begin{array}{c}\text { Study } \\
\mathrm{n}=15\end{array}$ & $\begin{array}{c}\text { Control } \\
\mathrm{n}=13\end{array}$ & $\begin{array}{c}\text { Study } \\
\mathrm{n}=15\end{array}$ & $\begin{array}{c}\text { Control } \\
\mathrm{n}=13\end{array}$ \\
& 20.27 & 22.23 & 39.33 & 24.69 \\
Average & 4.39 & 4.59 & 2.87 & 5.80 \\
Satandard Desviation & $\mathrm{t}=-1.158$ & $\mathrm{t}=8.639$ \\
& $\mathrm{p}=0.258$ & $\mathrm{p}=0.000$ \\
\hline
\end{tabular}

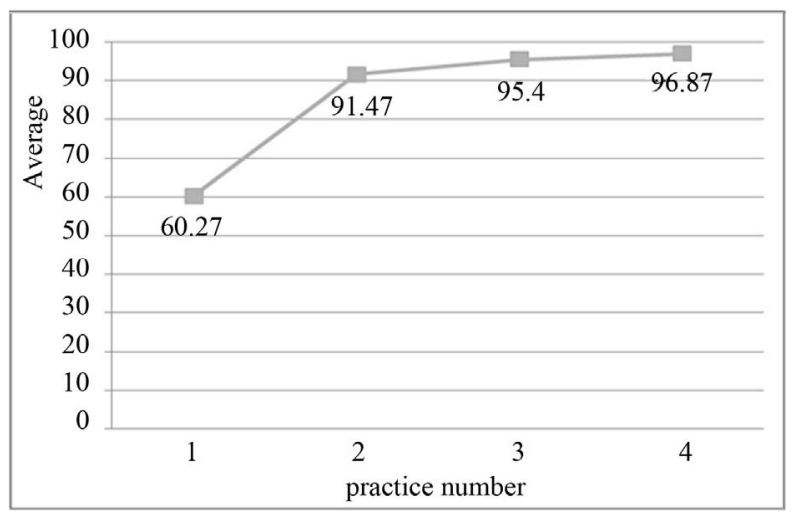

Figure 1. Behavior technical skills in taking Pap in the study group.

Table 3. Report samples before and after the educational intervention.

\begin{tabular}{ccccccccc}
\hline & \multicolumn{1}{c}{ GROUPS } \\
\hline \multirow{2}{*}{$\begin{array}{c}\text { Cytology } \\
\text { Report }\end{array}$} & \multicolumn{3}{c}{ STUDY } & \multicolumn{3}{c}{ CONTROL } \\
\cline { 2 - 9 } & \multicolumn{2}{c}{ Before } & \multicolumn{2}{c}{ After } & \multicolumn{2}{c}{ Before } & After \\
\hline \multirow{2}{*}{ No. } & $\%$ & No. & $\%$ & No. & $\%$ & No. & $\%$ \\
Inadequate & 6 & 40.0 & 2 & 13.3 & 1 & 7.7 & 2 & 15.4 \\
Adequate & 9 & 60.0 & 13 & 86.7 & 12 & 92.3 & 11 & 84.6 \\
Total & 15 & 100 & 15 & 100 & 13 & 100 & 13 & 100 \\
\hline
\end{tabular}

The study group obtained $60 \%$ of smears classified as adequate before the educational intervention and $86.7 \%$ after. The control group obtained $92.3 \%$ classified as adequate cytology in the first evaluation and $84.6 \%$ in the second (Table 3 ).

\section{DISCUSSION}

Most staff obtained a level of knowledge medium in taking cervical smears in both the study group and in the control group before the intervention; this result is consistent with that reported Gutierrez [9] in 2006 where most staff also presented a medium level of knowledge. Also this result is related to what the program notes Continuous Quality Improvement of Health Care 19972000, based on the program of the National Campaign for Quality Health Services in Mexico, where he mentions that there is a low level of compliance with the official rules and technical standards for the care of the major health problems, including cervical cancer is by $64 \%$ [8].

When analyzing the results by section, most of personal show weaknesses in knowledge of anatomy of the female genital area, second in Mexican official standards for cervical cancer screening and thirdly incorrect implementation of the procedure. The most 
important weaknesses were located exploring the patient's condition to see if the test candidate, the indications and contraindications of screening, the frequency of Pap and the area where you get the material for cytology. This result agrees with Gomez Macias [10] where the staff are unknown about the basics of Mexican Official Standard and anatomic sites for sampling. Likewise, a study by Curiel-Valdes [11] says that with the same instrument to take samples but in different hands gets different quality material, which supports the theory that not only the instrument used, but how it is used and what the characteristics of the patient are, which determines the quality. It is also important to note that various studies report that it is not very important the type of profession who take the samples, but this skilled enough in the areas needed to provide quality care.

In general, the average both theoretical knowledge and practical skills was between medium and low in all participants prior to the application of the training program, indicating that both Nurses and Physicians are showing weaknesses in implementation screening. This finding agrees with a study by Arillo and Lazcano [12] in the state of Morelos, México, where they investigated the knowledge of health professionals on the prevention of cervical cancer, in which it was found that the average knowledge was of 4.74 on a scale of $0-10$, also a relevant fact is also unaware of the frequency with which women should be tested, most cases must be postulated that less than a year. These same authors mention that in the medical field about $50 \%$ of knowledge is valid for 5 10 years, which makes it necessary to update to avoid obsolescence of knowledge. In another study conducted in Zimbabwe by Tarwirexi [13] also found a low level of knowledge of health personnel on the predisposing factors for cervical cancer.

Knowledge is very important because as the service provider may make an assessment that is not relevant during the interview with the patient in order to know if is a candidate for screening, and this is a risk factor for users of the program, because they can perform the test who do not need it at that time or otherwise, might not it is performed for women who really deserve it. The above is based on Donabedian theory [14] who argues that the level of quality is the extent to which the care provided is able of achieving the most favorable balance of risks and benefits, and that the quality and the monetary cost are interrelated well, when attention is excessive (e.g. a test or procedure that is not necessary) and harmful, is more expensive and lower quality, when excessive attention is harmless, it is more expensive, but without increasing quality, which is a waste, since the customer also spends time and money to attend the service.

Another area in which failure was detected on knowledge of anatomy of the lower genital tract of women, specifically: the location of the endocervix, transformation zone, exocervix and, also unknown how cells are formed the transformation zone. Participants mentioned that they did not have training in the past year and those that had training only been theoretical and a few hours, also mentioned that there is no continuous monitoring of the program implementation of cervical cancer, at least in the seizure of Pap, which agrees with most of the countries in Latin America [15,16] where this health problem is very severe and does not have quality assurance systems that are external to official bodies.

The staff had failures to perform Pap skills in the following sections: guidance to the user, in the records, particularly in the identification of patient risk factors, and gynecological assessment before testing and during it, as well as in the implementation of the central technique (sampling, extended and fixation). The most important weaknesses were in the instrument identification, the obtaining the smears with the correct ends of the spatula, intensity of pressure, rotating the spatula, the cell sweep, and the fixation the specimen. These problems were solved in the study group after training.

The control group did not change the way of doing the procedure, nor considered important to do. The study group showed a significant improvement in their theoretical and practical skills. Both groups (study and control) were afraid to be evaluated, however in the study group decreased fear with the implementation of the first stage of training: the systematization of the experience, where participants through a panel shared each other the difficulties observed in the seizure of smear. This activity enriched the educational strategy.

For the study group practice phase was the most important because participants took cytology to patients in real situations and then in plenary session discussed the characteristics of the samples using an electron microscope, in this way it was possible to raise competence in this procedure. All practices were recorded through observation of a monitor who watched and guided the staff in all steps of the procedure, also applied the technique of peer review, they were evaluated and observed each other, learning from the mistakes of others. Teaching techniques were applied such as video, audio, and staining cytology samples demonstrations, modeling of the cervix, in addition to a special practice with lower mammalian (beef cervix) in which they developed their skills in a learning environment more favorable, since from a real anatomical piece perfected their practice. This methodology favored achieving the objectives.

Four evaluations were made, from the second practice the skills improved by $90 \%$ and this improvement was sustained in the remaining practices, as reflected in the lab report after the intervention, all participants study groups obtained a favorable result in the quality of the 
samples.

The educational intervention has a favorable effect on the theoretical and practical skills of health personnel. The educational model and the methodologies implemented in training favored the increase of knowledge and skills taking the smear. The quality of the samples was increased after training and that all specimens containing all specifications pointing Bethesda System, which involves a lower number of false negative results. This research expresses the need to increase employment skills including the "know", "doing" and attitudes, as it is important that health staff offer a quality service based on education, training, skills and experience appropriate.

Certification is a process in which most organizations are already integrating, the health sector is implementing the concepts and methodologies through the National Program for Quality Crusade, and so it is important that staff have skills necessary for all the basic procedures that correspond to priority health programs.

A major limitation in this study was the unavailability of directors to allow leave to train staff, as well as the weak evaluation culture. For future research it is suggested more measurements, six months and a year to verify that the increase in knowledge and skills are sustained over time.

\section{REFERENCES}

[1] Castellsagué Piqué, X. De Sanjosé, S. and Jose, F.X.J. (2007) Chapter 1: Epidemiology of HPV infection and cervical cancer. New preventive options. In: Human Papillomavirus and Cervical Cancer, Editorial Médica Panamericana, Madrid, 14-17.

[2] World Health Organization (2008) Experts call for improvements in the Americas to prevent deaths from cervical cancer. Autor, México.

[3] Aroch, C.A., Díaz-Sánchez, J.G., Zertuche, J.G. and Ohara, G. (2005) Colposcopic new technique to prevent cervical cancer. Journal of the Faculty of Medicine: National Autonomous University of Mexico (UNAM), 48, 47-51.

[4] Government of Mexico. Ministry of Health (2006) Mortality from cervical cancer by state and municipality. Autor, México.
[5] Government of México. National Institute of Statistics, Geography and Informatics (2006) World Cancer Day. Autor, México.

[6] Government of México. Ministry of Health (2007) National Health Program 2007-2012. Autor, México.

[7] Salvetto, M. (1999) Cervical cancer: the cost of poor quality. Health Newsletter quality. http://www.icas.net/icasweb/precio.htm

[8] Government of Mexico (2001) Program action: The crusade for quality health services. Ministry of Health.

[9] Gutiérrez Enríquez, S.O. (2006) Quality cervical cytology and associated factors in health personnel of San Luis Potosí. Doctoral Dissertation, University of Guadalajara, México.

[10] Gómez, M., Díaz, I., et al. (2002) Evaluation of an educational intervention for improvement of the Early Detection of Cancer. Journal of Nursing, Mexican Social Security Institute 10, 137-144.

[11] Curiel, V.J. (2002) Pap smear: the importance of the transformation zone and how to obtain an adequate sample. México Medical Gazette, 138, 259-265.

[12] Arillo-Santillan, E., Lazcano-Ponce, E., et al. (2000). Knowledge of health professionals on the prevention of cervical cancer. Alternative medical education. Journal of Public Health from México, 42, 34-42. doi:10.1590/S0036-36342000000100007

[13] Tarwirexi, F., Chirenje, Z.M. and Rusakakikos, S. (2003) Cancer of the cervix: Knowledge, beliefs and screening behaviours of heatlh workers in Mudzi District in Mashonaland East Provice Zimbabwe. The Central African Journal of Medicine, 49, 83-86.

[14] Donabedian, A. (1992) Warranty and monitoring of the quality of medical care. National Public Health Institute, Cuernavaca.

[15] Almonte, M., Murillo, R., Sánchez, G., Jerónimo J., Salmeron, J., Ferreccio, C., Lazcano-Ponce, E. and Herrero, R. (2010) New paradigms and challenges in the prevention and control of cervical cancer in Latin America. Journal of Public Health from México, 52, 544-599. doi:10.1590/S0036-36342010000600010

[16] Noreña-Quiceno, C. and Tamayo-Acevedo, L.S. (2010) Cervical cancer: Analysis of the quality of a program. Aquichán, 10, 52-68. 